OPEN ACCESS

Citation: M. Hasaninejad, Z. Jamzad, Saeid Afsharzadeh, H. Saeidi (2021) Chromosome counts of eight Iranian endemic species of Nepeta L. (Lamiaceae). Caryologia 74(1): 53-61. doi: 10.36253/caryologia-729

Received: November 24, 2019

Accepted: April 26, 2021

Published: July 20, 2021

Copyright: (c) 2021 M. Hasaninejad, Z. Jamzad, S. Afsharzadeh, H. Saeidi. This is an open access, peer-reviewed article published by Firenze University Press (http://www.fupress.com/caryologia) and distributed under the terms of the Creative Commons Attribution License, which permits unrestricted use, distribution, and reproduction in any medium, provided the original author and source are credited.

Data Availability Statement: All relevant data are within the paper and its Supporting Information files.

Competing Interests: The Author(s) declare(s) no conflict of interest.

\section{Chromosome counts of eight Iranian endemic species of Nepeta L. (Lamiaceae)}

\author{
Maryam Hasaninejad ${ }^{1}$, Ziba Jamzad ${ }^{2}$, Saeid Afsharzadeh ${ }^{1, *}$, Hojjatol- \\ LAH SAEIDI ${ }^{1}$ \\ ${ }^{1}$ Department of Biology, Faculty of Biological Science and Technology, University of Isfa- \\ han, Isfahan, Iran. \\ ${ }^{2}$ Research Institute of Forests and Rangelands, Agricultural Research, Education and \\ Extension Organization (AREEO), Tehran, Iran. \\ ${ }^{*}$ Corresponding author. E-mail: s.afshar@sci.ui.ac.ir
}

\begin{abstract}
In this survey, the chromosome counts of eight Nepeta L. species were investigated and the karyotypic diversity among these species was studied. The examined species belong to $N$. cephalotes Boiss. species group, namely $N$. eremokosmos Rech.f., $N$. gloeocephala Rech. f., cephalotes Boiss., N. pungens (Bunge) Benth., N. ispahanica Boiss., $N$. mahanensis Jamzad \& Simonds, $N$. hormozganica Jamzad and $N$. denudata Benth. collected from different habitats in Iran. The ploidy levels, karyotype formula, chromosome length range, total karyotype length, several karyotype asymmetries values and Stebbins classification were determined in this study. Results showed the same chromosome number, $2 \mathrm{n}=2 \mathrm{x}=18$ for all studied species. The basic chromosome number for the above mentioned species are $\mathrm{x}=9$. Also, the smallest chromosome length is 1.02 $\mu \mathrm{m}$ in $N$. mahanensis. The largest chromosome length is $2.3 \mu \mathrm{m}$ in $N$. ispahanica. The chromosomes of species were metacentric or submetacentric. According to the Stebbins classification, these species were located into three classes $1 \mathrm{~A}, 2 \mathrm{~A}$ and $3 \mathrm{~A}$. The chromosome numbers for six of studied species are reported here for the first time.
\end{abstract}

Keywords: chromosome number, cytotaxonomy, endemics, Lamiaceae, karyotype, Iran, Nepeta L.

\section{INTRODUCTION}

The family Lamiaceae consists of 7173 species in 236 genera worldwide. Many of its species have a great importance due to their economic values (Harley et al. 2004). Nepeta L. (catmint) is a genus belonging to the subfamily Nepetoideae (Cantino et al. 1992). It is one of the largest genera within Nepetoideae, growing as annual, herbaceous perennial and fruticose plants (Rechinger 1982; Jamzad 2003a, 2012; Kaya and Dirmenci 2008).

Endemic species, constituting valuable floristic elements are those which are confined to a particular geographic region. The narrow endemic species are not only scientifically interesting but also very important from conservation point of view. Therefore, the identification of endemic plants, their 
conservation and genetic resources are interesting for the scientific community (Ghaffari et al. 2005). In Iran, there are 165 endemic taxa of Lamiaceae including 42 endemic Nepeta species. Iran is one of the centers of diversity for the genus Nepeta (Jamzad et al. 2003b).

Most species of the Lamiaceae have medicinal values. There are numerous known species in the family that are used as analgesic drugs in traditional medicine (Uritu et al. 2018). Medicinal properties of the Lamiaceae species are often ascribed to their high content of volatile compounds (Khoury et al. 2016) and glandular hairs represent important sites for the synthesis of natural bioactive compounds (Giuliani et al. 2020). Nepeta is an important genus in Lamiaceae and is specified by terpenoid-type compounds and phenolic constituents, which exert several activities such as an antimicrobial, repellent against major pathogen vector mosquitoes, insecticide, larvicide against Anopheles stephensi, cytotoxic anticarcinogen, antioxidant, anticonvulsant, analgesic, anti-inflammatory agent, and antidepressant, disclosing its importance in medicinal and agricultural fields (Süntar et al. 2018).

Species of this genus have been studied in the fields of morphology-anatomy (Kaya and Dirmenci 2008; Acar et al. 2011), palynology (Jamzad et al. 2000; Celenk et al. 2008; Moon et al. 2008). Chemical composition (Baser et al. 2000; Asgarpanah et al. 2014) and molecular phylogeny (Jamzad et al. 2003b). The lack of sufficient data on the karyomorphology of the genus is probably due to the small size of its chromosomes (Esra et al. 2020).

Many karyological data concerning chromosome numbers of the genus have already been reported as $\mathrm{x}=$ 6, 7, 8, 9, 11, 12, 15, 13, 17, 18. (IPCN, http://www.tropicos. org/Project/IPCN, Darlington and Wylie, 1955; Goldblatt and Johnson 1979-2017; Chen et al. 2018) and there are a few reports from Iran (Aryavand 1977; Ghaffari and Kelich 2006; Kharazian et al. 2013; Payandeh et al. 2015;
Akbarpur Mamagani et al. 2016; Hasaninejad et al. 2020). It should be admitted that the numerical variation in chromosome numbers within a genus is quite common.

The chromosome numbers and karyotype studies are not only useful in predicting morphological similarities and diversity among species, but also, they are valuable sources of taxonomic and biosystematic information. Regarding to the complexities in taxonomy of the genus Nepeta, the phylogenetic relationships of species and the chromosomal evolutionary trend may elucidate the systematics, and lead to a comprehensive infrageneric classification of the genus. In this study, we aim to do a cytotaxonomic study of the genus, and follow up the process of chromosomal evolution and its use in the classification of this genus. Here we report part of our results on the chromosome counts of a natural species group, recognized previously as section Capituliferae Benth. p.p. (Bentham 1848) and group five (Jamzad et al. 2003b), with mostly Iranian endemic species.

\section{MATERIALS AND METHODS}

Seeds of 8 species were collected from different habitats of Iran are, as listed in Table 1. The voucher specimens of the examined species are preserved in the herbarium of the Research Institute of Forests and Rangelands of Iran (TARI).

For mitotic studies, the seeds were germinated at $25{ }^{\circ} \mathrm{C}$ on wet filter paper in petri dishes. After germination, roots of $0.5-1 \mathrm{~cm}$ were selected for pretreatment. Root tips were pretreated for $1 \mathrm{~h}$ in a-monobromonaphthalene at $4{ }^{\circ} \mathrm{C}$, washed and fixed in Carnoy solution (3:1 absolute ethanol glacial acetic acid) overnight. The root tips were hydrolyzed for 5-8 minutes in $1 \mathrm{~N} \mathrm{HCl}$ at room temperature, washed and stained in $2 \%$ Hematoxylin for $1 \mathrm{~h}$.

Table 1. The voucher details of studied Nepeta species.

\begin{tabular}{lll}
\hline No & Species & Geographical Location \\
\hline 1 & N. cephalotes Boiss. & Iran, Tehran, Jajroud highway towards Jajrood 1544 m, Golipour, 106883, TARI. \\
2 & N. denudata Benth. & Iran, Hamedan, near Razan, 1889 m, Golipour, 106879, TARI. \\
3 & N. eremokosmos Rech.f. & Iran, Semnan, Sorkhe, 1355 m, Golipour, 106880, TARI. \\
4 & N. gloeocephala Rech. f. & Iran, Yazd, Taft, Nasr Abad, Gilok village in the river, 2800m, Mirhoseini, 95002, TARI. \\
5 & N. hormozganica Jamzad & Iran, Hormozgan, N. Bandar Abbas, N. slop of M. Bokhon, 834 m, Ajani,105647, TARI. \\
6 & N. ispahanica Boiss. & Iran, Kerman, Rayen to the first Garow, Fazlabad village road, 2618 m, Golipour, 106881, TARI. \\
7 & N. mahanensis Jamzad \& Simonds & Iran, Kerman East Silo Mahan-Before to Khaki-Asphalt Road, Hossein Abad 1980 m, Golipour, \\
& & I06882, TARI. \\
8 & N. pungens (Bunge) Benth. & Iran, Chaharmahal va Bakhtiari, Shahrekord, Babahidar, the first road to the village of Sepidaneh, \\
& & 2340 m, Ajani \& Hasaninejad, 107079, TARI. \\
\hline
\end{tabular}


OLYMPUS BH-2 photomicroscope provided the clearest mitotic metaphase among 5 cells and measured by Micro Measure software 3.3.

Karyotypes were prepared and chromosome pairs were classified according to Levan et al. (1964) and the metacentric and sub-metacentric chromosomes were symbolized using the letters $\mathrm{m}$ and $\mathrm{sm}$, respectively. The chromosomes were arranged according to their lengths. The long arm (q), short arm (p), mean length of the chromosome (CL), and total chromosome length (TCL) were measured. Karyotype symmetry was determined according to Stebbins (1971) and total form percentage $(\mathrm{TF}, 100 \times \Sigma \mathrm{S} / \mathrm{C})$ (Huziwara 1962).

\section{RESULTS}

There was no difference between basic chromosome numbers of the eight studied species and they were $\mathrm{x}=$ 9. The details of each species are as follow:

Nepeta cephalotes is an Irano-Turanian endemic species and grows in central and northwest of Iran. This species showed a diploid chromosome number $2 \mathrm{n}=2 \mathrm{x}$ $=18$ (Figure $1 \mathrm{~A})$ and the basic chromosome number of $\mathrm{x}=9$. Karyotype consisted of 9 pairs of submetacentric chromosomes (Tables 2, 3; Figure 2A). The chromosome length ranged from 1.14 to $2.07 \mu \mathrm{m}$. The chromosome number of this species is reported here for the first time.

Nepeta denudata is an endemic perennial species, with a distribution range in central, northeast, and west of Iran. The results showed that this species is also diploid with chromosome number of $2 \mathrm{n}=18$ (Figure 1B). The karyotype was formed of eight pairs of submetacentric and one pair of metacentric chromosomes (Tables 2, 3; Figure 2B). The mean length of chromosome varied from 1.1 to $1.9 \mu \mathrm{m}$. The chromosome number of this specie is reported here for the first time.

Nepeta eremokosmos is a narrow endemic species. It grows in a limited geographical area in central Iran. The studied specimens showed a diploid chromosome number of $2 \mathrm{n}=2 \mathrm{x}=18$ in this taxon (Figure $1 \mathrm{C}$ ) and basic chromosome number of $\mathrm{x}=9$. Karyotype in this taxon consisted of 9 pairs of submetacentric chromosomes

Table 2. Karyotype formula according to Levan et al. (1964) of the studied Nepeta species: 2n- Chromosome number; x- Basic chromosome number; PL- Ploidy level; KF- Karyotype formula R- range; SC- The shortest chromosome length; LC- The longest chromosome length.

\begin{tabular}{lcccccc}
\hline No & Species & $2 \mathrm{n}$ & $\mathrm{x}$ & $\mathrm{PL}$ & $\mathrm{KF}$ & $\mathrm{R}(\mathrm{SC}-\mathrm{LC})(\mu \mathrm{m})$ \\
\hline 1 & N. cephalotes & 18 & 9 & $2 \mathrm{x}$ & $9 \mathrm{sm}$ & $1.14-2.07$ \\
2 & N. denudata & 18 & 9 & $2 \mathrm{x}$ & $8 \mathrm{sm}+\mathrm{m}$ & $1.17-1.90$ \\
3 & N. eremokosmos & 18 & 9 & $2 \mathrm{x}$ & $9 \mathrm{sm}$ & $1.31-1.99$ \\
4 & N. gloeocephala & 18 & 9 & $2 \mathrm{x}$ & $6 \mathrm{~m}+3 \mathrm{sm}$ & $1.05-1.98$ \\
5 & N. hormozganica & 18 & 9 & $2 \mathrm{x}$ & $5 \mathrm{~m}+4 \mathrm{sm}$ & $1.15-1.73$ \\
6 & N. ispahanica & 18 & 9 & $2 \mathrm{x}$ & $7 \mathrm{sm}+2 \mathrm{~m}$ & $1.47-2.30$ \\
7 & N. mahanensis & 18 & 9 & $2 \mathrm{x}$ & $9 \mathrm{~m}$ & $1.02-1.74$ \\
8 & N. pungens & 18 & 9 & $2 \mathrm{x}$ & $7 \mathrm{sm}+2 \mathrm{~m}$ & $1.11-2.12$ \\
\hline
\end{tabular}

Table 3. Karyomorphological parameters of studied Nepeta species: AR- arm ratio; CI- Mean centromeric index; p- Mean length of the short arm; q- Mean length of the long arm; TCL- The total chromosome length of the haploid complement; CL- Mean length of the chromosome; TF- Total form percentage and Stebbins- Classification of Karyotypes in relation to their degree of asymmetry according to Stebbins (1971).

\begin{tabular}{|c|c|c|c|c|c|c|c|c|c|}
\hline No & Species & $\begin{array}{c}\mathrm{AR}(\mathrm{L} / \mathrm{S}) \\
(\mu \mathrm{m})\end{array}$ & $\mathrm{CI}(\mu \mathrm{m})$ & $\mathrm{P}$ mean $(\mu \mathrm{m})$ & $\mathrm{q}$ mean $(\mu \mathrm{m})$ & TCL & $\begin{array}{l}\text { CLmean } \\
(\mu \mathrm{m})\end{array}$ & $\mathrm{TF}(\%)$ & Stebbins \\
\hline 1 & N. cephalotes & 2.18 & 0.32 & 0.47 & 1.10 & 14.47 & 1.61 & 31.41 & $3 \mathrm{~A}$ \\
\hline 2 & N. denudata & 2.12 & 0.33 & 0.50 & 1.06 & 13.98 & 1.55 & 32.01 & $3 \mathrm{~A}$ \\
\hline 3 & N. eremokosmos & 1.91 & 0.35 & 0.56 & 1.07 & 14.61 & 1.62 & 34.37 & $2 \mathrm{~A}$ \\
\hline 4 & N. gloeocephala & 1.58 & 0.36 & 0.59 & 0.93 & 13.71 & 1.52 & 38.81 & $2 \mathrm{~A}$ \\
\hline 5 & N.hormozganica & 1.67 & 0.33 & 0.52 & 0.87 & 12.58 & 1.40 & 37.47 & $1 \mathrm{~A}$ \\
\hline 6 & N. ispahanica & 1.83 & 0.35 & 0.64 & 1.18 & 16.44 & 1.83 & 35.28 & $2 \mathrm{~A}$ \\
\hline 7 & N. mahanensis & 1.34 & 0.43 & 0.58 & 0.78 & 12.29 & 1.37 & 42.79 & $1 \mathrm{~A}$ \\
\hline 8 & N. pungens & 1.89 & 0.35 & 0.57 & 1.08 & 14.86 & 1.65 & 34.60 & $2 \mathrm{~A}$ \\
\hline
\end{tabular}




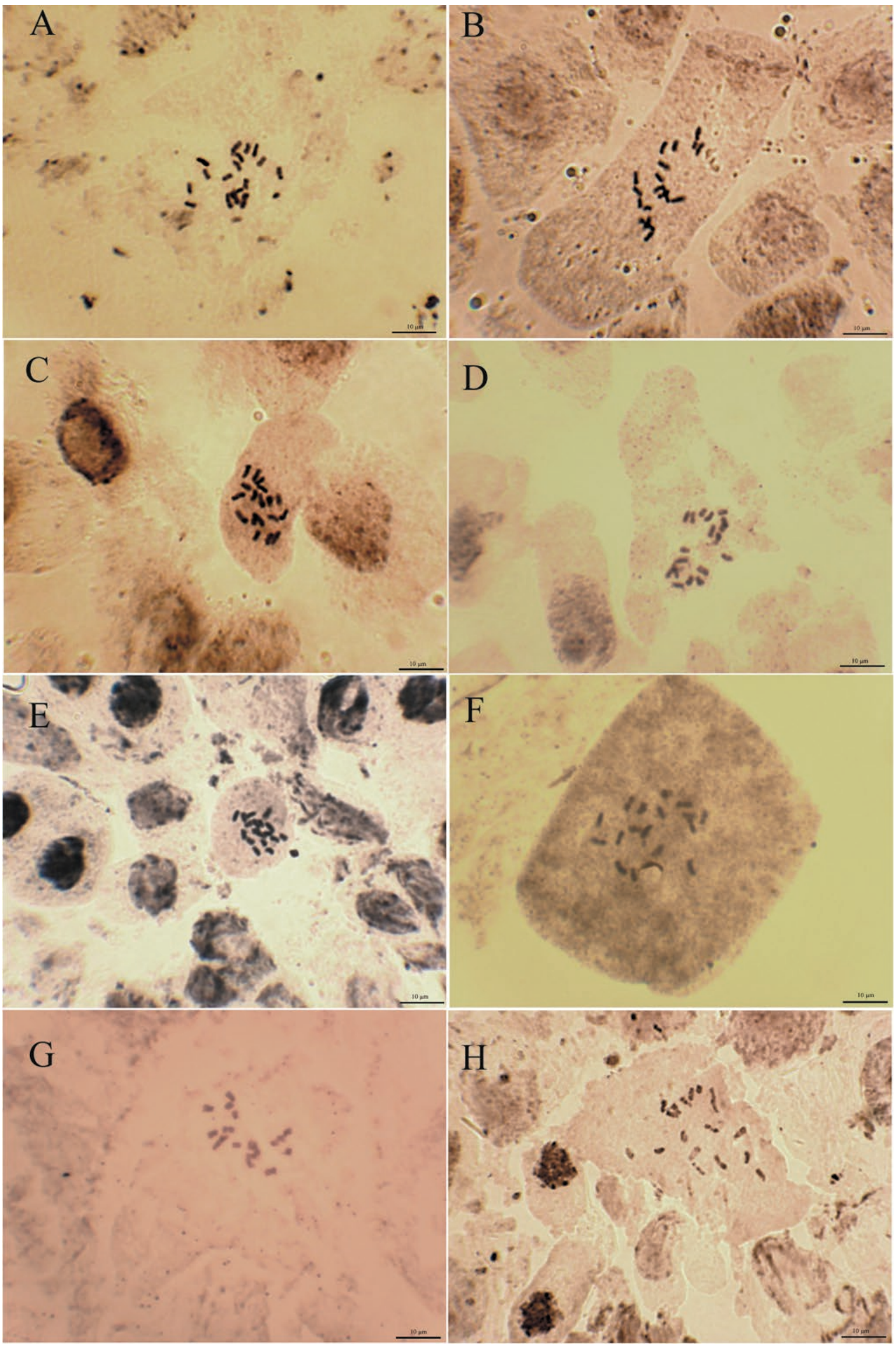

Figure 1A-H. Somatic chromosomes of Nepeta (A- N. cephalotes; B- N. denudata; C- N. eremokosmos; D- N. gloeocephala; E- N. hormozganica; F- N. ispahanica; G- N. mahanensis; H- N. pungens). Scale bars: $10 \mu \mathrm{m}$. 

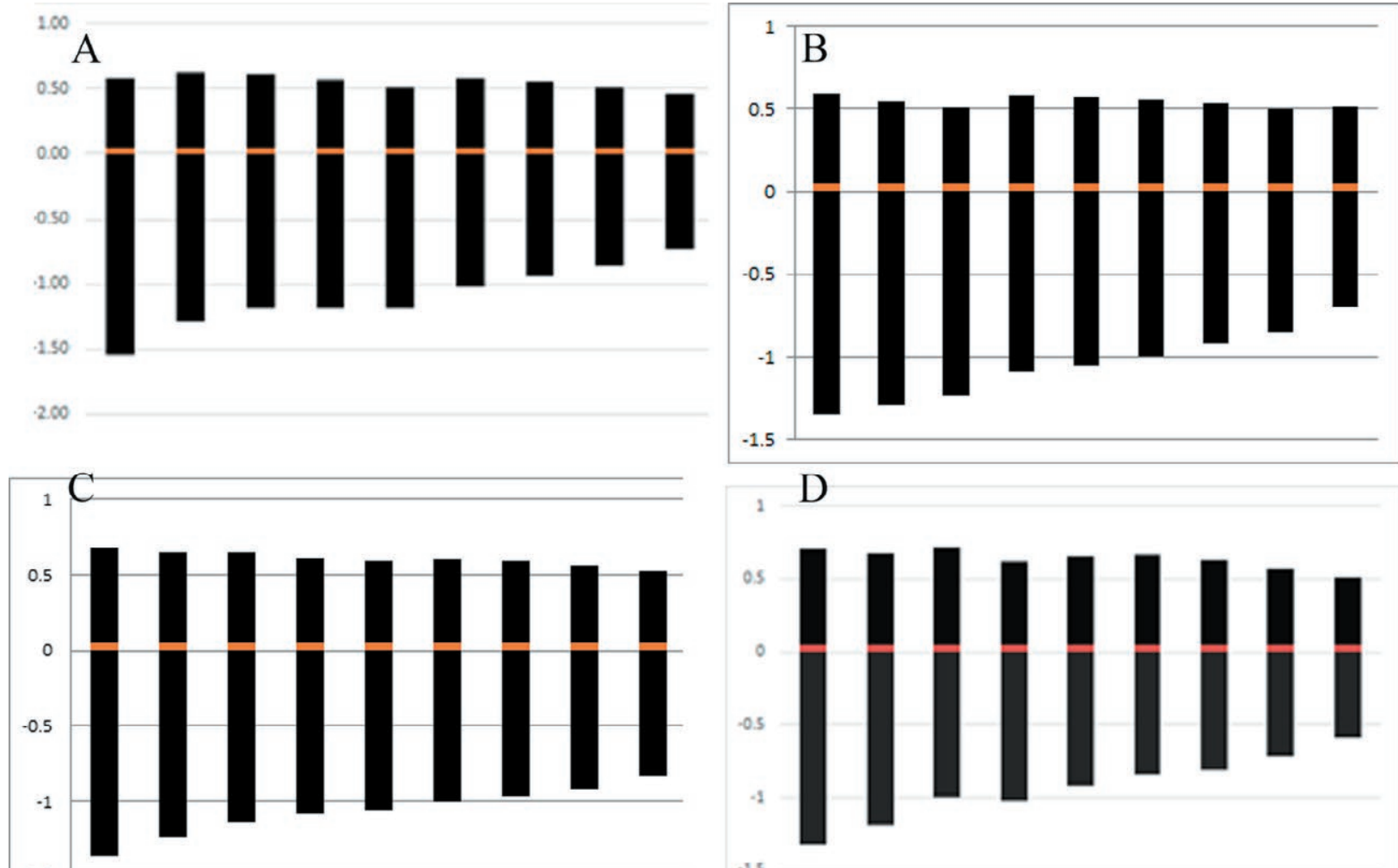

$-1.5$
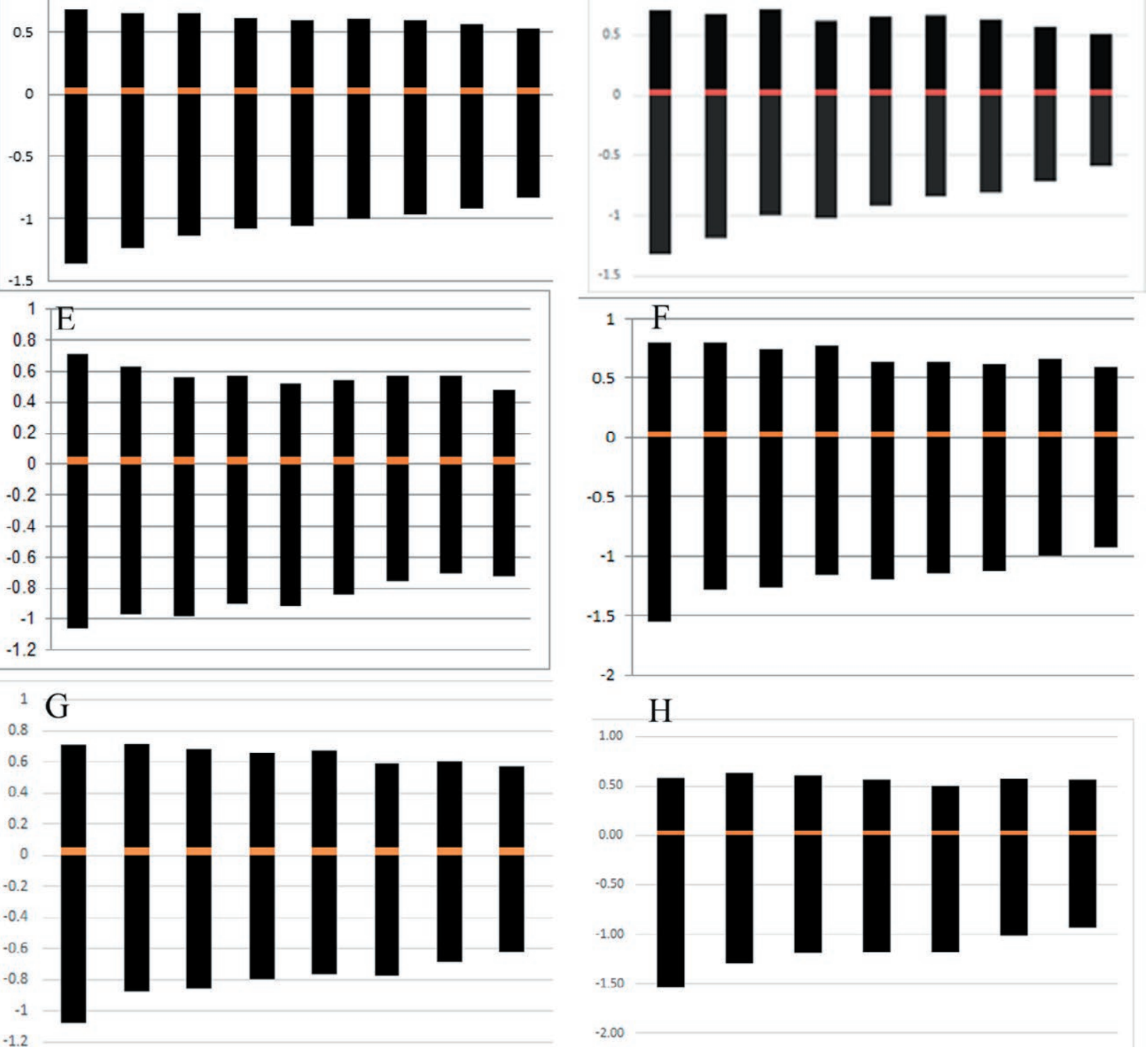

Figure 2A-H. Idiograms of the karyotypes of Nepeta (A- N. cephalotes; B- N. denudata; C- N. eremokosmos; D- N. gloeocephala; E- N. hormozganica; F- N. ispahanica; G- N. mahanensis; H- N. pungens). Scale bars: $10 \mu \mathrm{m}$. 
(Tables 2, 3; Figure 2C). The chromosome length is 1.3 to $1.9 \mu \mathrm{m}$. This is the first chromosome count for this species.

Nepeta gloeocephala is an endemic species found in few localities in central Iran. Chromosome number of $2 \mathrm{n}=2 \mathrm{x}=18$ and somatic chromosome count in this species showed an $\mathrm{x}=9$ (Figure 1D). Karyotype was included 6 pairs of metacentric and 3 pairs of submetacentric chromosomes in this specie (Tables 2, 3; Figure 2D). The chromosome length varied from 1.05 to 1.98 $\mu \mathrm{m}$. This is the first chromosome number reported for this taxon.

Nepeta hormozganica is an annual species from Saharo-Sindian region, growing in south Iran. The diploid chromosome number of $2 \mathrm{n}=18$ was counted in this species (Figure 1E). Five chromosome pairs were metacentric and four pairs were submetacentric (Tables 2, 3; Figure 2E). The chromosome length was in the range of 1.1 to $1.7 \mu \mathrm{m}$. The chromosome number of this species is reported here for the first time.

Nepeta ispahanica is a regional endemic annual species growing in west, northeast, central, south, and southeast of Iran. It is also distributed in Afghanistan. The studied specimens showed a diploid chromosome number of $2 \mathrm{n}=2 \mathrm{x}=18$ (Figure $1 \mathrm{~F}$ ) and basic chromosome number of $\mathrm{x}=9$. N. ispahanica had 7 pairs of submetacentric and 2 pairs of metacentric chromosomes (Tables 2, 3; Figure 2F). The chromosome length ranged from 1.4 to $2.2 \mu \mathrm{m}$. This is the first chromosome count for this species.

Nepeta mahanensis is a narrow endemic annual species. This species grows in a limited geographical area in Kerman province. Chromosome number in this species was $2 \mathrm{n}=18$ (Figure $1 \mathrm{G}$ ). The karyotype was formed of 9 pairs of metacentric chromosomes (Table 2, 3; Figure $2 \mathrm{G})$. The chromosome length varied from 1.02 to 1.74 $\mu \mathrm{m}$. This is the second report on the chromosome numbers of this species. The result of this study is in agreement with the previous report conducted by Payandeh et al. (2015) for $N$. mahanensis $(\mathrm{x}=9 ; 2 \mathrm{n}=18)$.

Nepeta pungens is a regional endemic species with wide distribution in central, northwest, west, northeast and southwest of Iran, Afghanistan, Turkmenistan and Central Asia. Nepeta pungens $(2 \mathrm{n}=2 \mathrm{x}=18)$ had 7 pairs of submetacentric and 2 pair of metacentric chromosomes (Figure $1 \mathrm{H}$ ). The chromosome length was in the range of 1.1 to $2.1 \mu \mathrm{m}$. This is the second report on the chromosome numbers of this species (Table 2, 3; Figure $2 \mathrm{H})$. However, the result of this study was not in agreement with the previous report conducted by Kharazian et al. (2013) for the $N$. pungens $(\mathrm{x}=11 ; 2 \mathrm{n}=22)$.

\section{DISCUSSION}

According to the Index to Plant Chromosome Numbers (IPCN, http://www.tropicos.org/Project/IPCN) (Goldblatt and Johnson 1979-2017), in Lamiaceae, the chromosome numbers vary from $2 \mathrm{n}=10$ to $2 \mathrm{n}=240$ in different genera and species. Alloplipoid and autoploid changes can be an important reason for this diversity. Extensive cytological studies of the different genera, including Thymus L., Ajuga L., Lamium L., Salvia L., Scutellaria L. and Elsholtzia Willd. had revealed the presence of diploid, tetraploid, hexaploid and octaploid species in the family Lamiaceae (Rather et al. 2018).

The chromosome numbers together with other factors can alter breeding strategy in plants (Fehr 1991; Contreras and Ruter 2011). Genome size can be estimated by measuring chromosomal data. Therefore, chromosome size is directly related to evolution (Mehra and Bawa 1972; Contreras and Ruter 2011; Esra et al. 2020).

The results of our study show that the examined species have $2 \mathrm{n}=18$ chromosome numbers and the basic chromosome numbers are $\mathrm{x}=9$.

Different researchers have suggested $x=8,9$ and 17 as the most common primary and secondary base numbers for the genus Nepeta (Gill 1972, 1979; Aryavand 1977; Saggoo 1983; Bir and Saggoo, 1984; Hasaninejad et al. 2020). The previous studies support the results of our study (Kaczmarek 1957; Gill 1979, 1984; Ghaffari and Kelich 2006; Saggoo et al. 2011; Kharazian et al. 2013; Payandeh et al. 2015; Akbarpur Mamagani et al. 2016; Hasaninejad et al. 2020), reporting the base chromosome number, $\mathrm{x}=9$ for Nepeta as a common number.

The studied species in this research had small chromosomes according to the classification of Lima-DeFaria (1980), with mean chromosome lengths (CLm) ranging from 1.37 to $1.83 \mu \mathrm{m}$ (Table 3 ). Whereas Baden (1983) argued that the karyotype details studies are difficult because of the small size of chromosomes.

Although the chromosome number of all studied Nepeta species was the same $(2 \mathrm{n}=18)$, their karyotype formulas were different, $9 \mathrm{sm}$ of $N$. cephalotes and $N$. eremokosmos and $9 \mathrm{~m}$ of $N$. mahanensis and $8 \mathrm{sm}+\mathrm{m}$, $6 \mathrm{~m}+3 \mathrm{sm}, 5 \mathrm{~m}+4 \mathrm{sm}, 7 \mathrm{sm}+2 \mathrm{~m}$ and $7 \mathrm{sm}+2 \mathrm{~m}$ of $N$. denudate, N. gloeocephala, N. hormozganica, N. ispahanica and $N$. pungens, respectively.

Baden (1983) reported the metacentric and submetacentric karyotype formula for $N$. sibthorpii Benth. and Kharazian et al. (2013), suggested the metacentric, sub-metacentric and metacentric point karyotype formula, which confirms our results.

$N$. cephalotes is distinguished by having the highest AR and the lowest CI values, and N. mahanensis by 
having lowest AR, TCL and CL values, $N$. isphanica by having the highest TCL and CL values; $N$. denudata by having the lowest AR value (Table 2).

It was found that all studied Nepeta species are in classes 1A, 2A and 3A based on Stebbins classification. $3 \mathrm{~A}$ species are more asymmetric or more advanced than class 1A species. Thus, $N$. cephalotes and $N$. denudate are more symmetric and $N$. hormozganica and N. mahanensis are more asymmetric. This study suggested that TF\% varied from 31.41 to 42.79 . N. mahaensis was distinguished by having the highest TF\%, N. cephalotes by having the lowest TF\% (Table 3).

Kharazian et al. (2013) reported $2 \mathrm{n}=22$ for $N$. pungens, which is in line with the previously reported base numbers (Chen et al. 2018). In our study, the chromosome number of $N$. pungens was counted $2 \mathrm{n}=18$, which is contrary to the previous reports. In this case of variability, Gill (1979) reported the intra-specific races for some of Nepeta species, or the case may be incorrect identification of the studied specimen.

Moreover, N. mahanensis was reported with $2 \mathrm{n}=18$ by Payandeh et al. (2015). In our report, the basic chromosome number is $\mathrm{x}=9$, which is fully in agreement with the results of our study for this species.

All studied species are either Iranian or regional endemics and showed chromosome numbers of $\mathrm{x}=9$. Srivastava (2012) believed that, there is a probability of base number $\mathrm{x}=9$ at the phylogenetic root of the Nepe$t a$, but annual species are considered to be the most evolved species in the genus (Jamzad et al. 2003b). As it is shown here for four annual Nepeta species ( $N$. ispahanica, N. mahanensis and $N$. hormozganica), the base number is $\mathrm{x}=9$, which does not support Sirvastava's idea. Previous literatures indicate that the genus Nepeta has a heterogeneous set of chromosome numbers. Considering the close phylogenetic relationship among the studied species (Jamzad et al. 2003b), it may be inferred that the similar chromosome numbers approve their close phylogenetic relationships. Future comprehensive cytotaxonomic studies and inferring the results on the Nepeta phylogenetic tree may elucidate the evolutionary trends in the genus and lead us to better understanding of the evolutionary values of chromosome numbers.

Most frequent count of the base chromosome number in Nepeta is $\mathrm{x}=9$. Whereas, in most species of Lamiaceae, the base chromosome numbers are different. The chromosome number as $2 \mathrm{n}=30$ is typical in some genera including Origanum, Clinopodium L., Micromeria Benth., Satureja L., Thymus etc. (Esra et al. 2020). In genus Caryopteris Bunge the chromosome number was reported as $2 \mathrm{n}=26$ and $\mathrm{x}=16$ in genus Chelonopsis Miq. was (Chen et al. 2018). Huang et al. (1996) reported that the basic chromosome number was $\mathrm{x}=8$ in Eriophyton Benth.. Phlomoides Moench is known to have a base chromosome number of $\mathrm{x}=11$, which is distinct from the base number $\mathrm{x}=10$ in Phlomis L. (Fang et al. 2007). Scutellaria is one of the largest genera within Lamiaceae that also has a complex chromosomal variation as at least 14 different chromosome numbers have been found for the genus $2 \mathrm{n}=14,16,18,20,22,24,26$, $28,30,32,34,44,60,88$. The basic chromosome number $\mathrm{x}=13$ in East and Southeast Asia, $\mathrm{x}=12$ in America and $\mathrm{x}=11$ in North Africa and Eurasia are predominating (Ranjbar and Mahmoudi 2013).

Whereas all studied species were homoploid, but according to previous studies (Gill 1972; Bir and Saggoo 1979, 1984; Saggoo 1983; Chen et al. 2018; Hasaninejad et al. 2020), aneuploidy and dysploidy changes had role in taxa evolution. Variation in the chromosome numbers is one of the important factors in the process of evolution (Srivastava 2012). However, all these species were not affected by chromosome number variation.

The results of this study provided a considerable contribution to the cytotaxonomic data of the genus Nepeta.

\section{REFERENCES}

Acar M., Ozcan T., Satil F., Dirmenci T. 2011. A comparative anatomical study on two endemic Nepeta L. species (N. baytopii and N. sorgerae). Biological Diversity and Conservation. 4(3):58-70.

Akbarpur Mamagani A., Mahmoodi Kordi F., Mohajjel Shoja H. 2016. New chromosome counts in Nepeta crassifolia an endemic medicinal plant from Iran. 14th Internatianl and Iranian Genetics Congress.

Aryavand A. 1977. In IOPB chromosome number reports LVII. Taxon. 26: 443-452.

Asgarpanah J., Sarabian S., Ziarati P. 2014. Essential oil of Nepeta genus (Lamiaceae) from Iran: a review. The Journal of Essential Oil Research. 26(1):1-12.

Baden C. 1983. Chromosome numbers the Nepeta sibthorpii group (Lamiaceae). Willdenowia. 13:337340.

Bentham G. 1848. Labiatae, In A. Candolle (Eds), Prodromus Systematis Naturalis Regni Vegetabilis. Vol. 12, p. 27-603. Treuttel and Wurtz, Paris.

Bir S.S., Saggoo M.I.S. 1984. Cytological studies on the family Labiatae from Gharwal Himalayas. In: G.S. Paliwal (Eds), The Vegetational Wealth of the Himalaya. pp. 471-482.

Cantino PD., Harley RM., Wagstaff SJ. 1992. Genera of Labiatae: Status and classification. In R.M. Harley 
and T. Reynolds (Eds), Advances in Labiate Science. p.511-522. Royal Botanic Gardens, Kew. London.

Celenk S., Dirmenci T., Malyer H., Bicakci A. 2008. A palynological study of the genus Nepeta L. (Lamiaceae). Plant Systematics and Evolution. 276:105-123.

Chen Y.P., Zhao F., Peng H., Xiang C.L., Funamoto T. 2018. Chromosome numbers of 24 taxa of Lamiaceae from Southwest China. Caryologia 71 (4) 298-306.

Contreras R.N., Ruter J.M. 2011. Genome Size Estimates and Chromosome Numbers of Callicarpa L. (Lamiaceae). Hort Science. 46: 4 567-570.

Darlington C.D., Wylie A.P. 1955. Chromosome Atlas of Flowering Plants, George 2nd Ed Allen and Unwin, London. 134-155.

Esra M., Tuncay D., Turan A., Türker Y., Taner Ö. 2020. Karyotype studies on the genus Origanum L. (Lamiaceae) species and some hybrids defining homoploidy. Caryologia. 73(2): 127-143.

Fang L.Q., Pan Y.Z., Gong X. 2007. A karyomorphological study in the monotypic genus Lamiophlomis and five species in Phlomis (Lamiaceae). Acta Phytotax Sin. 45(5):627-632.

Fehr W.R. 1991. In Principles of cultivar development: Theory and technique, Polyploidy, ed Fehr W.R. (Macmillan, New York, NY). Vol. 1, pp 59-65.

Ghaffari M., Hejazi A., Pourahmad A. 2005. New chromosome counts in nine endemic species. Folia Geobotanica 40:435-440.

Ghaffari S.M., Kelich K. 2006. New or rare chromosome counts of some angiosperm species from Iran II. Iranian Journal of Botany. 12. 81-86.

Gill L.S. 1972. Chromosome Numbers in West-Himalayan Bicarpellate Species II. Bulletin of the Torrey Botanical Club. 99(1):36-38.

Gill L.S. 1979. Cytotaxonomic studies of the tribe Nepeteae (Labiatae) in Canada. Genetica. 50:111-117.

Gill L.S. 1984. The incidence of polyploidy in the west Himalayan Labiatae. Revue de Cytologie et de Biologie Végétales, le Botaniste. 7:5-16.

Giuliani C., Bottoni M., Ascrizzi R., Santagostini L., Papini A., Flamini G., Fico G. 2020. Scutellaria brevibracteata subsp. subvelutina (Rech.f.) Greuter \& Burdet: morphological and phytochemical characterization. Natural Product Research.

Goldblatt P., Johnson D.E. 1979-2017. Index to plant chromosome numbers. St. Louis: Missouri Botanical Garden.

Harley R.M., Atkins S., Budantsev A.L., Cantino P.D., Conn B.J., Grayer R., Harley M.M., De kok R.P.J., Krestovskaja T., Morales R., Paton A.J., Ryding O. And Upson T., 2004. Labiatae. K. Kubitzki (Ed), The Families and Genera of Vascular Plants, Vol. 6, pp.
167-275. Springer-Verlag, Berlin, Heidelberg, New York.

Hasaninejad M., Jamzad Z., Afsharzadeh S., Saeedi H. 2020. Cytological studies on four endemic species of Nepeta L. (Lamiaceae). Iranian Journal of Botany. 26(1): 62-66.

Huang R.F., Shen S.D., Lu X.F. 1996. Studies on the chromosome number and polyploidy for a number of plants in the north-east Qinghai-Xizang Plateau. Acta Botanica Boreali-Occidentalia Sinica. 16(3):310-318.

Huziwara Y. 1962. Karyotype Analysis in Some Genera of Compositae. VIII. Further Studies on the Chromosomes of Aster. American Journal of Botany. 49:116119.

Jamzad Z., Harley, M. M., Ingrouille, M., Simmonds, M. S. J., Jalili, A. 2000. Pollen exine and nutlet surface morphology of the annual spcies of Nepeta L. (Lamiaceae) in Iran. In: M. M. Harley, C. M. Morton \& S. Blackmore (Editors) Pollen and Spores: Morphology \& Biology. Royal Botanic Gardens, Kew. pp. 385-379.

Jamzad Z., Grayer R.J., Kite GC., Monique S.J., Simmonds M.I., Jalili A. 2003a. Leaf surface flavonoids in Iranian species of Nepeta (Lamiaceae) and some related genera. Biochemical Systematics and Ecology. 31:587-600.

Jamzad Z., Chase M., Ingrouille M., Simmonds M.S.J., Jalili A. 2003b. Phylogenetic relationships in Nepeta $L$. (Lamiaceae) and related genera based on ITS sequence data. Taxon 52: 21-32.

Jamzad Z. 2012. Nepeta L. in Assadi \& al. (Eds.). Flora of Iran. Research Institute of Forests \& Rangelands, Tehran. 76: 454-609.

Kaczmarek F. 1957. Nepeta cataria var. citriodora. als Droge zur Gewinnung von Atherischem Ol. Planta Medica (Stuttgart). 5:51-56.

Kaya A., Dirmenci T. 2008. Nutlet Surface Micromorphology of the Genus Nepeta L. (Lamiaceae) in Turkey. Turkish Journal of Botany. 32:103-112.

Kharazian N., Zamani Shourabi S., Yousefi M. 2013. Chromosome count and karyotype study of eleven Nepeta L. (Lamiaceae) species from Iran. Biological Diversity and Conservation. 6(1):76-87.

Khoury M., Stien D.R., Eparvier V., Ouaini N., El Beyrouthy M. 2016. Composition and Antimicrobial Activity of Their Essential Oils. Evidence-Based Complementary and Alternative Medicine. Volum 2016.

Levan A., Fredgak K., Sandberg A.A. 1964. Nomenclature for centromeric position on chromosomes. Hereditas. 52: 201-220.

Lima De Faria A. 1980. Classification of genes, rearrangements and chromosomes according to the chromosome field. Hereditas. 93:1-46. 
Mehra P.N., Bawa K.S. 1972. Cytogenetical evolution of hardwoods. Nucleus 15: 64-83.

Moon H.K, Vinckier S, Smets E, Huysmans S. 2008. Comparative pollen morphology and ultrastructure of Mentheae subtribe Nepetinae (Lamiaceae). Review of Palaeobotany and Palynology. 149: 174-186.

Payandeh M., Bordbar F., Mirtadzadini M., Bakhshi Khaniki G.R. 2015. New chromosome counts for Nepeta (Lamiaceae) from flora of Iran. Biological Diversity and Conservation. 8/2. 70-73.

Ranjbar M., Mahmoudi C. 2013. Chromosome numbers and biogeography of the genus, Scutellaria L. (Lamiaceae). Caryologia. 66(3):205-214.

Rather A.A., Banday A., Shabir P.A., Nawchoo I.A., Ganaie K.A. 2018. Cytology and Pollination Biology of Lamiaceae: A Review.Research \& Reviews.Journal of Botanical Sciences.7(2): 22-32.

Rechinger K.H. 1982. Nepeta L. In K.H. Reghinger (Eds), Flora Iranica. p.108-216. Akademische Druck-U. Verlagsanstalt, Graz, Austria.

Saggoo M.I.S. 1983. Cytomorphological studies on plants of economic importance of Bicarpellatae from India. Ph.D. Thesis. 259, p. Punjabi University Patiala, India.

Saggoo M.I.S., Srivastava D.K., Grewal P. 2011. Meiotic studies in 14 species of the Nepeta L. (Lamiaceae) from cold desert regions of Lahaul-Spiti and adjoining areas of Northwest-Himalaya, India. Cytologia. 76:231-236.

Srivastava D.K. 2012. Cyto-morphological diversity in species of Labiatae and Scrophulariaceae from LahaulSpiti and adjoining areas. Ph.D Thesis. Department of Botany, Punjabi University Patiala, Patiala, Punjab (India).

Süntar I., Nabavi S.M., Barreca D., Fischer N., Efferth T. 2018. Pharmacological and chemical features of Nepeta L. genus: Its importance as a therapeutic agent. Phytotherapy Research. 32(2):185-198.

Uritu C., Teodor Mihai C., Dumitrita Stanciu G., Dodi G. 2018. Medicinal Plants of the Family Lamiaceae in Pain Therapy: A Review. Pain Research and Management. Volum 2018. 